\title{
Assessment of 1.5 Mm Low Profile Titanium Miniplate As a Tension Band in Treatment of Mandibular Parasymphyseal Fractures
} \author{
Hawary ${ }^{3}$ \\ ${ }^{1}$ Faculty of dentistry, October 6 university, Egypt \\ ${ }^{2}$ Professor of Oral and Maxillofacial Surgery, Faculty of Oral and Dental Medicine, Cairo University, Egypt \\ ${ }^{3}$ Lecturer of Oral and Maxillofacial surgery, Faculty of Oral and Dental Medicine, Cairo University, Egypt
}

Mohammad Adel Helmy*1, Mostafa Kamal EL-Din Ezz ${ }^{2}$, Sameh Tarek Mekhemer ${ }^{2}$ and Hesham El-Sayed El-

Submission: February 23, 2017; Published: March 08, 2017

*Corresponding author: Mohammad Adel Helmy, BDS, Faculty of Dentistry, Cairo University, Egypt, Email: drmah84@gmail.com

\begin{abstract}
Purpose: The study was carried out to assess the use of $1.5 \mathrm{~mm}$ low profile titanium miniplate as a tension band in the treatment of mandibular parasymphyseal fractures.

Patients and Methods: The study was performed on 12 patients; 10 males and 2 females suffering from mandibular parasymphyseal fractures with/without other fractures in the maxillofacial region. Patients were selected from those attending the outpatient clinic, Oral and Maxillofacial Surgery Department in both, Faculty of Oral and Dental Medicine, Cairo University and Faculty of Dentistry, October 6th University. The selected patients were randomly divided into two equal groups. All patients were treated under general anesthesia with standard nasal endotracheal intubation.
\end{abstract}

Results: The use of $1.5 \mathrm{~mm}$ low profile titanium miniplates shows no statistical significance $(\mathrm{P}<0.05)$ in the treatment of mandibular parasymphyseal fractures when compared to $2.0 \mathrm{~mm}$ titanium miniplates.

Conclusion: There were no differences detected in results between $1.5 \mathrm{~mm}$ low profile titanium miniplate and $2.0 \mathrm{~mm}$ titanium miniplate when used as a tension band.

Keywords: Low profile miniplate; Parasymphyseal fractures; Tension band; Osteosynthesis

\section{Introduction}

Mandible is a very prominent and vulnerable bone on the face, since the projected chin is a favored target of adversary's lower jaw fractures are twice as common a major role in the mastication, speech and deglutition. Its fractures result in severe loss of function and disfigurement [1]. The aim of mandibular fracture treatment is the restoration of anatomical form and function, with particular care to establish the occlusion. Traditionally, this has been achieved by immobilizing the jaws using various wiring techniques. In the past 2 decades, interest has increased for different methods of open reduction and internal fixation (ORIF) [2]. There are multiple alternatives in treatment of mandibular parasymphyseal fracture with miniplate technique as regard site and number of the plates applied with controversy in selection of the most successful technique.
Hence the purpose of the study was to assess the $1.5 \mathrm{~mm}$ low profile titanium miniplate as a tension band in the treatment of mandibular parasymphy-seal fractures.

\section{Patients and Methods}

\section{I.Patient Selection}

a) Inclusion criteria: patients included suffered from trauma to the face and diagnosed with mandibular parasymphyseal fractures. Their age ranged from 18-50 with mean age 25 years old.

b) Exclusion criteria: patients with any comminuted fractures, associated pathology or bone disease and uncontrolled debilitating systemic disease. 


\section{II.Pre-operative Procedures}

\section{a)Case History}

b) Clinical Examination: General examination was achieved to evaluate any concomitant injury in the body. Local examination for the fractured mandible was preformed both extraorally and intraorally by inspection and palpation.

c) Radiographic examination: Preoperative radiological examination was performed mainly by using: digital Panoramic radiograph, Submentovertex projection. Any other radiographic views indicated for the associated fractures depending on the patient's medical condition were performed.

\section{III.Patients Grouping}

The selected patients were randomly divided into two equal groups:

a)Group I: Treated by open reduction and internal fixation through intra-oral approach using $2.0 \mathrm{~mm}$ Titanium miniplate at the inferior border of the mandible and a $1.5 \mathrm{~mm}$ low profile Titanium miniplate as tension band.

b)Group II: Treated by open reduction and internal fixation through intra-oral approach using two $2.0 \mathrm{~mm}$ Titanium miniplate one at the inferior border of the mandible and the other as a tension band.

\section{IV.Study design}

a)Pre-operative preparation and investigations: Clinical digital photographs, preoperative radiographs, informed consent were taken. Wound debridement and care of any soft tissue injury were performed.

i.Medications: Antibiotic* was prescribed for maximum 48 hours as a prophylaxis against infection, Non-steroidal antinflamatory drug** $75 \mathrm{mg}$ ampules to control pain and edema, Antiseptic mouthwash***.

Emergency intermaxillary fixation was performed utilizing Ivy loops as a temporary means of fixation following closed reduction to decrease pain and susceptibility to infection due to segments mobility.

*Unasyn: Each vial contains: 500 mg sulbactam sodium + $1000 \mathrm{mg}$ ampicillin, manufactured by Pfizer Egypt S.A.E Cairo, A.R.E.

** Voltaren: Diclofenac sodium $75 \mathrm{mg} / \mathrm{amp}$ manufactured by Novartis [3-5].

*** Antiseptol: Each bottle contains: Chlorhexidine Gluconate $0.1 \%$ manufactured by Kahira.

Standard laboratory investigations were requested. All selected patients were medically categorized asAmerican Society ofAnesthesiologists (ASA) class II. Patients were kept fasting at least six hours before the operation.

\section{V.Surgical procedures}

a.Induction and Site preparation: All the surgeries were performed under general anesthesia utilizing the nasotracheal intubation. Pa-tients were scrubbed and draped according to the standard protocol for intra-oral surgeries.

b.Approach and Exposure: The fractured site was exposed by a standard transoral vestibular approach and incising the men-talis muscle in an oblique manner to leave a generous cuff. Skeletonization of the mental nerve was performed in certain cases with oblique fracture line ending below the apices of 1 st or 2nd premolar; to avoid pressure injury to the mental nerve during retraction.

c.Fracture reduction and Fixation: Once the fractured segments had been reduced to the normal anatomical position, fixation was performed according to champy's ideal line of osteosynthesis. A titanium miniplate (6-holes) was contoured and adapted to the labial aspect of the mandible and fixed at the inferior border of the mandible along lower Champy's line with 6 bicortical $2.0 \mathrm{~mm}$ screws after drilling under copious saline irrigation to prevent thermal bone injury. In group I, a low profile titanium miniplate (4-holes) was adapted superiorly as a tension band and fixed at the upper champy's line with 4 monocortical $1.5 \mathrm{~mm}$ screws after drilling under copious irrigarion (Figure 1). In group II, a titanium miniplate (4-holes) was adapted superiorly as a tension band and fixed at the upper champy's line with 4 monocortical $2.0 \mathrm{~mm}$ screws after drilling under copious irrigation.

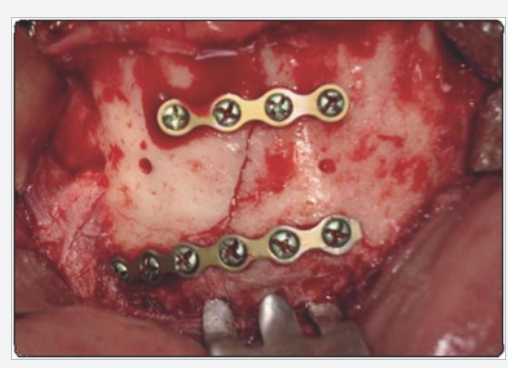

Figure 1: Intraoperative clinical photograph showing reduction and fixation utilizing 6 holed 2.0 titanium miniplate and 4-holed low profile titanium miniplate placed superiorly as a tension band and fixed with 4 monocortical $1.5 \mathrm{~mm}$ screw of $5 \mathrm{~mm}$ length.

d.Debridement and closure: The intraoral incision was closed in layers after copious irrigation and debridement of the operating field. Arch bars were removed except in cases that had subcondylar fracture that was treated by closed reduction and elastic traction for 10 days. Surgical dressing was applied over the wound, and a pressure dressing is placed extraorally for approximately 24 hours to prevent hematoma formation.

\section{b)Postoperative instructions and medications}

Good oral hygiene was emphasized by instructing the patient to perform tooth brushing, and to rinse utilizing warm saline and 
mouth wash*. Semi-solid feeding was ordered for the patients on the second postoperative day and until the end of intermaxillary fixation period. Betadine 1\%: $120 \mathrm{ml}$ bottle contains povidine iodine $1 \%$, manufactured by The Nile company Cairo, A.R.E. Prophylactic Antibiotics* were prescribed for one week postoperatively to guard against infection. Anti-edemic** were prescribed to reduce post-operative edema and inflammation. Analgesics*** were also prescribed whenever needed to control post-operative pain.

\section{VI.Post-Operative follow up}

Patients were followed up both clinically and radiographically for a period of six months.

a.Clinical follow-up: This was performed at the following intervals: 2nd post-operative day (immediate post-operative), Weekly for the first month (sutures were removed after 1st week), Three months post-operative and Six months postoperative. It was performed to examine the presence of: wound dehiscence, infection and swelling, segment mobility, nonunion or malunion, any nerve deficit and any change in occlusion.

b.Radiographic follow-up: Digital Panoramic radiographs \& submentovertex projection was performed for all patients according to the following schedule: Immediate post-operative, One-month post-operative and Six months post-operative (Figure 2).

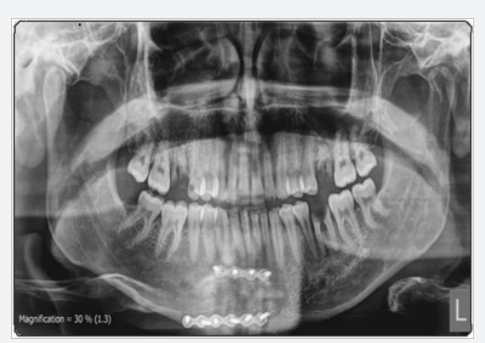

Figure 2: 6 months post-operative panoramic radiograph showing evidence of bone healing with no signs of infection around the screws.

c.Neuro-sensory examination: This was performed using single point objective method.

\section{Results}

Results shows that Wound dehiscence was ob-served in one patient $(8.3 \%)$ from the twelve that represent the whole study population. It occurred after one week post-operatively and managed with daily irrigation and prophylactic antibiotic therapy. Infection was observed in $16.7 \%$ of patients (one case) of the study group due to pulp necrosis of one of the neighboring teeth that was traumatized during the accident. It was treated endodontically under antibiotic coverage. It also happen in 33\% ( 2 cases) of the control group 4 weeks post-operatively. In one case it was due to pulp necrosis of tooth near fracture line and managed by root canal treatment and antibiotic medication.
While in the other, infection happened due to the presence of loose screw that was crossing the fracture line and it was managed by incision and drainage, removal of loose screw under antibiotic coverage. The difference between both groups was found to be statistically insignificant $(\mathrm{P}=0.33)$.

There was no segment mobility, non-union or malunion. Regarding occlusion, all patients return to their normal anatomic occlusion post-operatively. There was proper occlusion in all cases throughout the follow up period. In the present study, paresthesia was detected in all patients immediate postoperatively and gradually recovered totally one month postoperaively, this was attributed to trauma itself in some cases and due to stretching of mental nerve and soft tissue during operation. In group I, all patients suffered from paraesthesia immediate post operatively (100\%) that resolved by the 1 st week in 2 cases $(66.7 \%)$ and in the 2 nd week another 2 cases (33.3\%) had resolved, by the $3 \mathrm{rd}$ week one case resolved $(16.7 \%)$ and by the 4 th week another case had paraesthesia $(16.7 \%)$ that is uneventful in 3rd and 6th months follow up. In group II, all patients had paraesthesia immediate post-operatively (100\%) then resolved by the 1 st week in one case (83.3\%) and in the 2nd week 3 cases had resolved (33.3\%) and after 4 weeks another 2 cases had resolved. There was no statistical significance throughout follow up period between both groups regarding incidence of paresthesia $(\mathrm{P}<0.05)$ (Figure 3$)$.

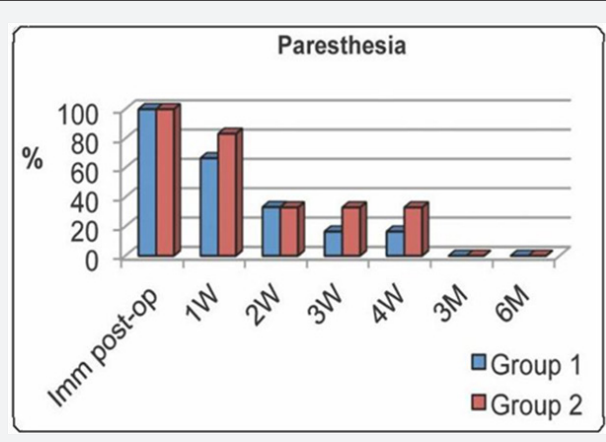

Figure 3: Bar-chart showing percentage of incidence of paresthesia in both groups at different intervals.

* $\quad$ Curam 1g: Each tab contains: 875 mg Amoxicillin + 125 mg Clavulinic acid, manufactured by Novartis.

** Alphintern: Each tab contains: Chymotrypsin 300 i.u + Trypsin 300 i.u, manufactured by Amoun Co. S.A.E, Cairo, Egypt.

*** Cataflam 50: Each tab contains: $50 \mathrm{mg}$ Diclofenac potassium, manufactured by Novartis $[6,7]$.

\section{Discussion}

The study was designed to assess the use of $1.5 \mathrm{~mm}$ low profile titanium miniplate as a tension band in the treatment of mandibular parasymphyseal fractures. It is malleable, thin, easily adapted and fixed in place using monocortical screws. This allows its use as a tension band without affecting tooth 
vitality and periodontium that was reported as a complication in association with other means of fixation in tension zone. This went in accordance to Levy et al. [3], Frost et al. [4] and Tonima et al. [5] as they stated that the smaller, more flexible bone plates have minimal stress shielding effect, with less hazard effect on mineral content of bone and its mechanical properties as compared to the effect of AO plate. This went in accordance with Champy et al. [7] who stated that smaller plates placed with monocortical screws in ideal osteosynthesis lines were needed to achieve healing under functional load without roots injury. And also in agreement with Potter and Ellis [8] who reported that thin malleable miniplates had minor complications.

In accordance to Kim and Nam [9] low-profile miniplates can be used in simple mandibular fractures regardless of the anatomic location. Also Frost et al. [4], Edward and David [10] stated that low-profile miniplates applied with monocortical screws, which decrease the likelihood of damage from screws to the inferior alveolar nerve or teeth in the area of plate placement. The main cause of injuries in the present study was the interpersonal violence; it accounts for $66.7 \%$ in group I (cases $02,03,04$ and 06 ) and 50\% in group II (cases 01, 02 and 06 ) followed by road traffic accidents $33.3 \%$ in group I (cases 01 and 05 ) and 50\% in group II (cases 03, 04 and 05). This was different from what showed by Ellis et al. [11] who reported in a large retrospective study of 2137 patients with mandibular fractures that $(43 \%)$ were caused by motor vehicle accidents, $(34 \%)$ by assaults, $(7 \%)$ as the result of a fall, (4\%) occurred in sport injuries, and the remainder had miscellaneous causes. This might be due to the cultural and behavioral difference between the environment of the present study and Ellis study.

Wound dehiscence was observed in one patient $(8.3 \%)$ from the twelve that represent the whole study population (case 03, group II). It occurred after one week post-operatively and managed with daily irrigation and prophylactic antibiotic therapy. It appeared as a suture break-down; this might be due incision above the mentalis muscle that lead to compromising the vascularity of the healing flap and allowed for tension over the suture line during mastication after returning back to normal dite. This went relatively in accordance with Zakaullah S, Kotrashetti SM and Maiya R [12] who reported that wound dehiscence was observed only in $5 \%$ of patients (one patient of total 20 patients of the study) and treated adequately with daily irrigation and antibiotic medication.

Infection was observed in $16.7 \%$ of patients (case 03) of the study group due to pulp necrosis of one of the neighboring teeth that was traumatized during the accident. It was endodontically treated under antibiotic coverage. It also happened in 33\% (cases 02 and 03 ) of the control group 4 weeks post-operatively. In Case 02 was due to pulp necrosis of tooth near fracture line and managed by root canal treatment and antibiotic medication. While in case 03 infection happened due to the presence of loose screw that was crossing the fracture line and it was managed by incision and drainage, removal of loose screw under antibiotic coverage. The difference between both groups was found to be statistically insignificant $(\mathrm{P}=0.33)$.

This was relatively in accordance with what stated by Kim and Nam [1-3] as they reported that Postoperative infection was observed in only one patient and treated adequately with incision and drainage and antibiotic medication and the plate was not removed. Also this was different from what stated by Ellis and Ghali [13] in their study (on 41 patients) of lag screw fixation of mandibular parasymphyseal and angle fractures as they reported two postoperative infections. One treated by sequestrectomy, the other to removal of a tooth in the fractureline. External pin fixation was undertaken after surgery.

On the other hand, There was no evidence of infection radiographically throughout study period except in case 03 in the control group $(16.7 \%)$ at one month; this was due to the presence of loose screw that affect the surrounding bone and need long period of healing to be disappear during radiographic examination. The difference between both groups was found to be statistically insignificant.

In the present study, there was no segment mobility, nonunion or malunion and this went in accordance with Zakaullah S, Kotrashetti S.M and Maiya R [12] as they reported that there were no cases of malunion or nonunion. There were no materialrelated failures such as plate fracture or loosening of hardware. Regarding occlusion, all patients return to their normal anatomic occlusion post-operatively, this was different from what have been reported by Kim and Nam [9] as there was one case had a Premature occlusal contact and was managed with elastic traction. The difference between both groups was found to be statistically insignificant. There was proper occlusion in all cases throughout the follow up period.

In the present study, paresthesia was detected in all patients immediate post-operatively and gradually recovered totally after one month post-operaively, this was attributed to the effect of trauma in some cases and due to stretching of mental nerve and soft tissue during operation. In group I, all patients suffered from paresthesia immediate post-operatively $(100 \%)$ that resolved by the 1 st week in cases 04 and 06 (66.7\%) after subsiding of the post-operative edema. In the 2 nd week cases 05 and 01 (33.3\%) had resolved as both cases underwent mental nerve skeletonization to minimize stretching of mental nerve and soft tissue intra-operatively; as the fracture line in both cases was oblique and need more exposure.

By the 3rd week case 02 resolved (16.7\%) and by the 4 th week case 03 had paresthesia (16.7\%) that is uneventful in 3rd and 6th months follow up, in both cases delayed resolution of paresthesia was due to soft tissue stretching intra-operatively as they did not underwent mental nerve skeletonization. In group 
II, all patients had paresthesia immediate post-operatively $(100 \%)$ then resolved by the 1 st week in case 06 (83.3\%) after post-operative edema subsided. In the 2 nd week cases 02,03 and 04 had resolved (33.3\%) as these cases underwent mental nerve skeletonization to minimize stretching of mental nerve and soft tissue intra-operatively as the fracture line in these cases was oblique and need more exposure. After 4 weeks, cases 01 and 05 had resolved, in both cases delayed resolution of paresthesia was due to soft tissue stretching intra-operatively as they did not underwent mental nerve skeletonization.

There was no statistical significance throughout follow up period between both groups regarding incidence of paresthesia $(\mathrm{P}<0.05)$. This went in accordance with Kim and Nam [9] as they reported that postoperative paresthesia is related to the trauma itself and the surgical approach and all patients with paresthesia recovered within 6 months postoperatively.

\section{Conclusion}

From the results of the present study, the follow-ing can be concluded that:

a. Low profile $1.5 \mathrm{~mm}$ titanium miniplate is good, malleable, thin, easily adapted and fixed in place using monocortical screws causing no injury to the tooth when used as a tension band.

b. There were no differences detected in results between $1.5 \mathrm{~mm}$ low profile titanium miniplate and $2.0 \mathrm{~mm}$ titanium miniplate when used as a tension band.

\section{References}

1. Stanley RB (1985) Pathogenesis \& evaluation of mandibular fracture. In: Methog RH: Maxillofacial trauma. Baltimore: William \& Wilkins, 136-47.
2. Booth PW, Schendel SA, Hausamen JE (2007) Maxillofacial Surgery. $\left(2^{\text {nd }}\right.$ edn), Churchill Livingstone, Vol 1 p. 74, London, UK.

3. Levy FE, Smith RW, Odland RM, Marentetto LJ (1991) mono-cortical miniplate fixation of mandibular angle fractures. Arch Otolaryngol. Head Neck Surg 117(2):149-152.

4. Frost DE, Tucker MR, White RP (1991) Small bone plate tech-niques for fixation of mandibular fractures. In: Rigid fixa-tion for maxillofacial surgery. Lippincotte Company, p.104, Philadelphia, USA.

5. Tonima AJ, Davidson CL, Klopper PJ , Linclau LA (1976) protection from stress in bone and its effects: experiment with stainless steel and plastic plates in dogs. J Bone Joint Surg 58(1):107-113.

6. Champy M, Loddè JP, Schmitt R, Jaeqer JH, Muster D (1978) mandibular osteosynthesis by miniature screwed plates via a buccal approach. J Maxillofac Surg 6(1): 14-21.

7. Worthinghan P, Champy M (1987) monocortical miniplate osteosynthesis. Otolaryngeal Clin North Am 20(3): 607-620.

8. Potter J, Ellis E (1999) treatment of mandibular angle fracture with a malleable noncompression miniplate. J Oral Maxil-lofac Surg 57(3): 288-292.

9. Kim YK, Nam KW (2001) treatment of mandible fractures using lowprofile titanium miniplates: preliminary study. Plast Reconstr Surg 108(1): 38-43.

10. Edward TJ, David DJ (1996) A comparative study of miniplates used in the treatment of mandibular fractures. Plast Recon Surg 97(6): 11501157.

11. Ellis E, Moos KF, El-Attar A (1985) Ten years of Mandibular Fractures : an analysis of 2,137 cases. Oral Surg Oral Med Oral Pathol 59(2): 120129.

12.Zakaullah S, Kotrashetti SM, Maiya Raj (2011) management of mandibular fractures using $1.3 \mathrm{~mm}$ low profile titanium miniplates. International Journal of Dental Clinic 3(2): 24.

13. Ellis E, Ghali GE (1991) lag Screw fixation of anterior mandibu-lar fractures. J oral Maxillofac Surg 49(1): 13-21.

\section{Your next submission with Juniper Publishers will reach you the below assets}

- Quality Editorial service

- Swift Peer Review

- Reprints availability

- E-prints Service

- Manuscript Podcast for convenient understanding

- Global attainment for your research

- Manuscript accessibility in different formats

( Pdf, E-pub, Full Text, Audio)

- Unceasing customer service

Track the below URL for one-step submission https://juniperpublishers.com/online-submission.php 